Marmara Medical Journal 2017; 30: 58-59

DOI: $10.5472 /$ marumj.306018

PHOTO-QUIZ

\title{
A late preterm infant with progressive respiratory distress
}

\author{
Secil ERCIN, Petek KAYIRAN, Tugba GURSOY
}

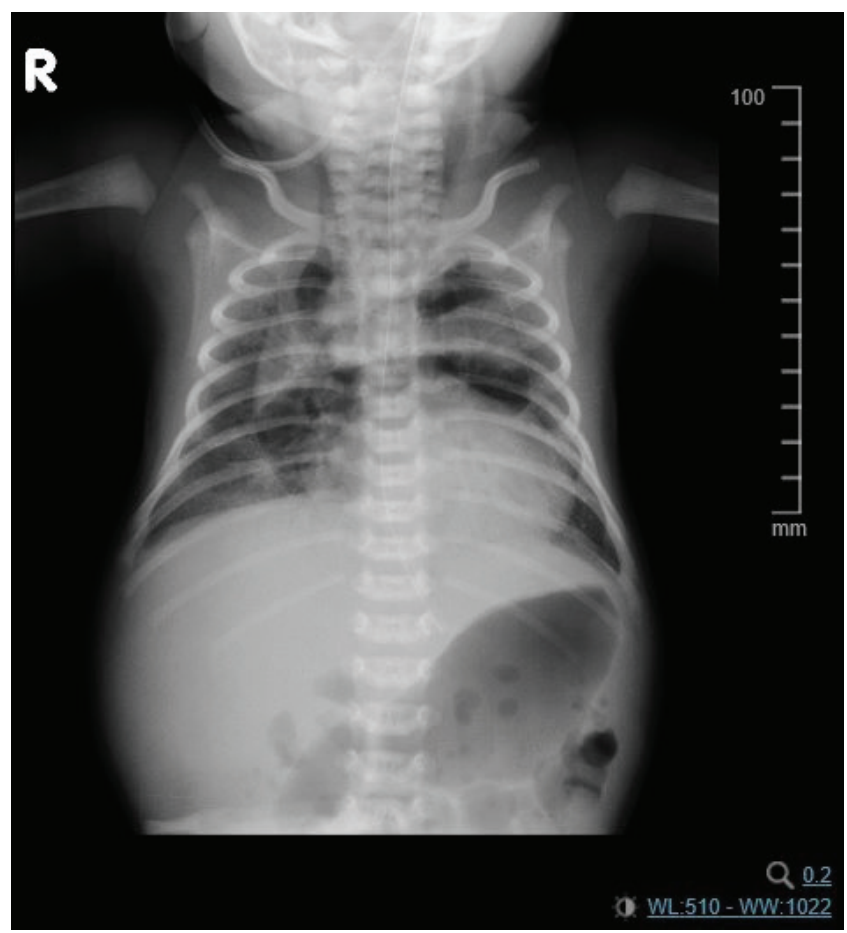

A $2300 \mathrm{~g}$ female baby was born at $36+4$ gestational age via caesarean section. Prenatal history was unremarkable. At 2 hours of age the baby was transferred to neonatal intensive care unit due to progressive respiratory distress and received poractant alfa as intubation-surfactant-extubation therapy after which $\mathrm{FiO} 2$ requirement decreased from 0.50 to 0.25 . At 34 hours of age, while she was still on nasal continuous positive airway pressure (CPAP), she had sudden deterioration with retractions, desaturation and bradycardia. The infant was immediately intubated and put on high frequency oscillatory ventilation (HFOV) after which her oxygen saturations and heart rate stabilized.

\section{What is your diagnosis?}

Figure 1. Chest X-ray

Secil Ercin (凶), Petek Kayiran

Neonatal Intensive Care Unit, Vehbi Koc Foundation American Hospital, Istanbul, Turkey

e-mail: secil_alpaslan@yahoo.com,secile@amerikanhastanesi.org

\section{Tugba Gursoy}

Neonatal Intensive Care Unit, School of Medicine, Vehbi Koc Foundation Koc University, Istanbul, Turkey 


\section{Pneumomediastinum}

Pneumomediastinum can be seen as a complication of nasal CPAP. Increased intraalveolar pressure leads to alveolar rupture into the perivascular space. Air then dissects along the vascular channels resulting in pneumomediastinum as it leaks into the mediastinum. Pneumomediastinum may precede the development of pneumothorax or can remain isolated. [1]. Management is supportive and directed at providing adequate gas exchange and minimizing the risk of further air leak. Angel wing sign typical for pneumomediastinum was seen on the X-ray of our patient (Fig 1). She was on HFOV for 28 hours when she was extubated. However, there was still some pneumomediastinum on X-ray. She received nasal CPAP for one more day and had no respiratory problem after the fourth postnatal day.

High frequency oscillatory ventilation may provide better ventilation and oxygenation in neonates with pulmonary air leak syndromes as it avoids large cyclic swings in tidal volume $[2,3]$.

\section{References}

1. Bejvan SM, Godwin JD. Pneumomediastinum: old signs and new signs. AJR AM J Roentgenol 1996;166:1041-8.

2. Zanardo V, Chiaranda M. High-frequency ventilation in the newborn infant Pediatr Med Chir 1985;7:801-7.

3. Gaylord MS, Quissell BJ, Lair ME. High-frequency ventilation in the treatment of infants weighing less than 1,500 grams with pulmonary interstitial emphysema: a pilot study. Pediatrics 1987; 79:915. 